\title{
ARQUITECTURA RURAL MENOR EN MAGALLANES II
}

\author{
MATEO MARTINIC B.* \& SAMUEL GARCIA O.**
}

\section{RESUMEN}

En lo referido a la arquitectura rural en Patagonia y Tierra del Fuego, se han estudiado los grandes cascos de estancias, esto es galpones, casas de administración, emplazamientos etc., todo ello correspondiente a un planteamiento de escala mayor. De forma simultánea ha existido una arquitectura rural de menores dimensiones que ha permanecido inadvertida en los estudios arquitectónicos y históricos realizados hasta el presente. Este artículo expone nuevos casos de Arquitectura Rural Menor, complementando un trabajo anterior sobre la materia. Estos corresponden entre otros a edificaciones con fines utilitarios para el cobijo animal (caballerizas y perreras), para el faenamiento alimentario cotidiano (carnicerías), la protección de vehículos de transporte (cocheras o garages) y para la preservación de alimentos (paperas). Del mismo modo se da cuenta de otros casos de construcciones especiales de arquitectura mínima tales como torres de agua, carniceras y mangas que con otras formas simples y complejas que hacen el todo edificado tradicional de los establecimientos productivos ganaderos en Patagonia y Tierra del Fuego. ${ }^{1}$

PALABRAS CLAVE: Arquitectura rural, patrimonio arquitectónico, Patagonia.

\section{RURAL MINOR ARCHITECTURE IN MAGALLANES II}

\begin{abstract}
Regarding rural architecture in Patagonia and Tierra del Fuego the big hulls of estancias have been studied. They include: storehouses, administration, emplacement, etc., all in relation to rural architecture from a macro scale perspective. Simultaneously, this considers a rural architecture of minor dimensions that had been ignored by architectural and historical studies till now. This article exposes new cases of Minor Rural Architecture, complementing a previous work in the matter. These cases are, among other things, the edifications with utilitarian purposes for animal shelter (stables, doghouses), for day-to-day slaughtering

Profesor Titular y Emérito, investigador Centro de Estudios del Hombre Austral, Instituto de la Patagonia, Universidad de Magallanes.mateo.martinic@umag.cl.

" Arquitecto, investigador asociado al Centro de Estudios del Hombre Austral, Instituto de la Patagonia, Universidad de Magallanes. samuelgarciaoteiza@gmail.com.

1 Fotografías y dibujos presentes en este artículo son de la autoria de Samuel García Oteiza@ con excepción a las indicas en epígrafes.
\end{abstract}


(butcher's), for the protection of transport vehicles (coach-houses, garages) and for the preservation of food (paperas). In the same way, other cases of special constructions of minimal architecture are mentioned, as water towers, butcher houses and corridors that with simple and complex forms define all the traditional buildings of stock-breeding productive establishments in Patagonia and Tierra del Fuego.

KEY WORDS: Rural architecture, architectural heritage, Patagonia.

\section{INTRODUCCIÓN}

Abundando acerca de lo expuesto con anterioridad sobre la materia (Martinic \& García 2014), en lo concerniente a las formas edificadas de que se trata, sólo parece haber regido (y regir) una norma general, esto es, el aislamiento para aquellas cuya función o destino genere olores molestos y ruidos, casos característicos de las carnicerías, establos, caballerizas y perreras; y la proximidad o incluso la contigüidad a edificios mayores (galpones, viviendas) para las de protección de bienes de uso habitual como las cocheras y las casetas de motores para la luz. Una fotografía reciente a vuelo de pájaro que muestra parte del casco de la estancia "Cullen" (Tierra del Fuego, Argentina), permite apreciar la variedad edificada $y$, en lo que interesa, la cantidad de construcciones menores en el conjunto y su distribución espacial (Fig. 1). Pero en la realidad cotidiana el visitante y viajero que llega a un casco de estancia (o pasa cerca del mismo) especialmente si se trata de un establecimiento antiguo de envergadura mayor o mediana, repara normalmente en las edificaciones que concitan su interés por volúmenes, tamaños y formas arquitectónicas, pasando la vista de largo por las edificaciones pequeñas $y$ sencillas o menos llamativas. De allí que sólo una visita con carácter de recorrido en búsqueda visual, observaciones detenidas y, finalmente, la reflexión acerca de la integración de cada caso en el conjunto edificado permite apreciar su importancia relativa.

A continuación se exponen, describen $y$ analizan los casos tipológicos más comunes de observar y también se hace mención de algunos que hacen excepción por su singularidad u originalidad.

\section{CASOS DE ESTUDIO}

\section{a) Caballeriza (pesebrera)}

Es esta una edificación utilitaria tradicional y por lo tanto infaltable en todo establecimiento ganadero patagónico en tanto dice con el buen trato y el cuidado que merece un animal de trabajo como es el caballo que, si antaño fue considerado un recurso imprescindible y hasta valioso en un tiempo histórico de tal actividad, para el transporte de personas y para las comunicaciones, sigue siéndolo actualmente para la tarea habitual de "recorrido de campo" realizada diariamente por ovejeros. De allî que los caballos, porque siempre los ha habido y hay en alguna cantidad en toda estancia ("tropilla") dependiendo de su importancia (dotación de ovinos), han recibido y reciben de sus amos y/o usuarios el cuidado que requieren para mantenerse sanos, en lo posible lozanos, y siempre en el mejor estado de servicio. Este cuidado se manifiesta en la alimentación (agua, forraje), limpieza de establos o pesebreras para los efectos de higiene animal y reparo de la intemperie para los periodos de descanso.

La construcción correspondiente está determinada por la cantidad de animales que son mantenidos en el establecimiento. Así el tamaño puede ser mediano en términos relativos al conjunto edificado del casco cuando se trata de estancias grandes o medianas, y variablemente menor en el caso de estancias pequeñas. Esta circunstancia ha originado la correspondiente subtipología, de modo que la edificación de que se trata asume mayor visibilidad para el observador de acuerdo con su tamaño y diseño constructivo. Así, en los cascos de antiguas estancias la caballeriza muestra notoriedad por su tamaño y diseño funcional pues incluye el espacio para el estacionamiento (descanso) de los equinos, calculado de acuerdo con la movilidad natural y la comodidad del animal; también un espacio amplio para la guarda del forraje para su alimentación y que se ubica en un altillo, a modo de piso superior, con un acceso desde el exterior a través de una puerta o abertura ad hoc para los efectos de carga o descarga; además el piso superior en sus extremos dispone de un intersticio de unos sesenta centímetros de 
ancho por el cual se arroja hacia el piso inferior el alimento al animal (Fig. 2). Por último se destina una dependencia anexa, separada de los otros espacios para la conservación del atalaje, recipientes y herramientas. Eventualmente este último espacio podía ser replicado en una suerte de balanceo estético para generar otra dependencia que bien podía ser utilizada como herrería. Para el tipo descrito se ha tenido a la vista las caballerizas de la antigua estancia "Rio Verde", estancia "Punta Delgada" y estancia "Avelina", en Magallanes, y las correspondientes a la estancia "Glencross" en Santa Cruz y estancia "María Behety", Tierra del Fuego, Argentina (Fig. 2a-2n). Ciertamente y sin embargo de las mencionadas y de otros ejemplos similares (o variaciones de los mismos) como es el caso de la caballeriza de la antigua estancia "Cerro Guido" (Ultima Esperanza, Magallanes, Chile), en el presente las construcciones correspondientes son comúnmente pequeñas en tamaño y modestas en su sencillo diseño.

\section{b) Perrera}

El perro ovejero, bien se sabe por el conocimiento común en Patagonia y Tierra del Fuego basado en la tradición, la literatura, el folklore y los viajes, es un animal doblemente apreciado por la gente de campo. Primero, como elemento de trabajo especializado muy eficaz para el manejo y control de ovejas en movimiento y segundo y en ocasiones no menos importante, como compañero fiel del trabajador rural. Inteligente como es de suyo el animal, bien enseñado y adiestrado por el ovejero que por el común lo selecciona dentro de una raza producto del mestizaje; aguantador y sufrido como ninguno, el perro ovejero ha sido, es y será siempre el animal de trabajo apreciado en Patagonia y Tierra del Fuego. Exige muy poco, además, carne para su alimentación diaria (el agua la encuentra por todas partes) y un reparo para descansar a cubierto de las variaciones climáticas. Eso es hoy día en que en un establecimiento rural o en partes habitadas del

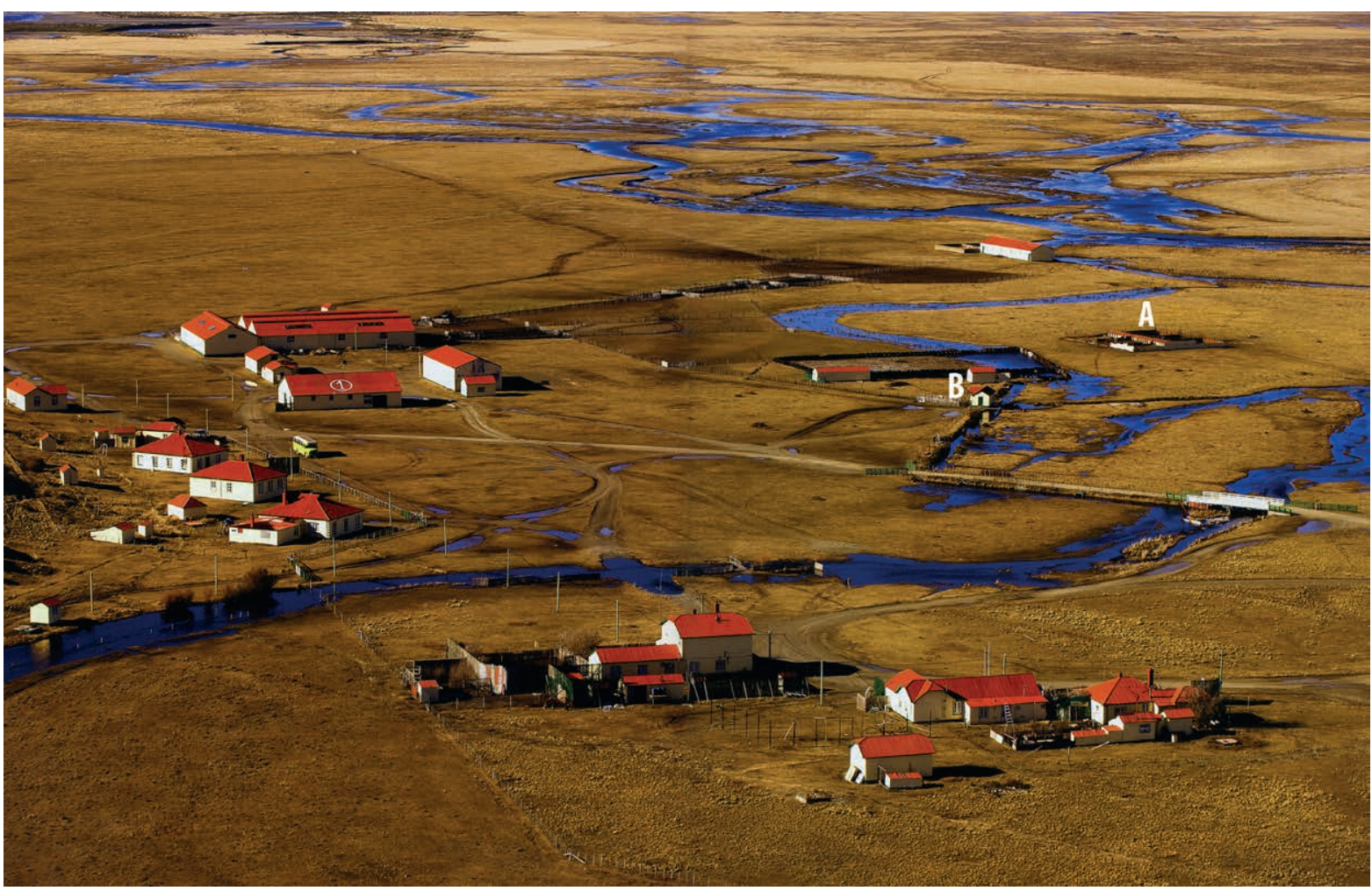

Fig. 1 Vista a vuelo de pájaro del casco de la estancia "Cullen" (Tierra del Fuego, Argentina) hacia 2000, (fotografía Florian von der Fecht (C). Puede apreciarse la gran cantidad de edificaciones mayores y menores que lo componen, entre ellas; las perreras (A) y carnicería (B). 
mismo la perrera no es más que un cajón, aunque, ciertamente hay excepciones. Pero antaño, durante la época de vigencia del latifundio en que reinaba una conciencia patronal de comprensión y consiguiente valorización acerca de la utilidad de animales como perros y caballos, las expresiones materiales de su cuidado también asumían formas edificadas con alguna preocupación y gracia. Las perreras, por ello, fueron materia de diseño y construcciones especiales desde que debian ser cobijos para el descanso de animales auxiliares de trabajo ganadero importados especialmente en una época, sobre la base de animales elegidos pertenecientes a razas especiales, todas variantes, del famoso "border collie" escocés ${ }^{2}$. De allí que una de las normas a tenerse en cuenta en la actividad cotidiana era la del cuidado de los animales y sus perreras.

Aunque no exista constancia específica sobre la materia en lo tocante a construcciones puede afirmarse que el cobijo debió ser inicialmente una preocupación personal del ovejero, pues debe tenerse presente que los primeros trabajadores contratados para el trabajo especializado con las ovejas lo fueron en Escocia, y/o en las islas Falkland (Malvinas) y estos debían venir con sus propios perros. De modo que su debido cuidado conformaba una obligación para los pastores contratados. Pero en una segunda fase del desarrollo ovejero patagónico con toda la planificación y diseño constructivo que siguió a la consolidación de la propiedad o tenencia latifundiaria, las perreras fueron incluidas sin embargo de la categoría inferior del género edificado. Esta época debió tener inicio alrededor de 1910, años más años menos. Aparecieron entonces dos tipo de perreras, ambos colectivos a modo de un complejo habitacional tipo celdas ; uno de forma rectangular, cuyo largo dependía del numero de animales (doce ejemplares comúnmente), en espacios individuales, construido de madera y zinc, con techo a dos aguas, elevación sobre el suelo con una base de hormigón o pilotes de madera (Fig. 3j) para el debido aislamiento de la humedad. En una fotografía publicada hacia 1924 (Fig. 3b) puede apreciarse este modelo de perrera

2 En época indeterminada de comienzos de los años de 1930 la Sociedad Ganadera y Comercial "Menéndez Behety" propietaria de la estancia "San Gregorio" adquirió a la firma escocesa Mac Pherson de Roybridge tres perros de bajo el título "La mansión de los perros ovejeros". En el catastro realizado durante esta investigación se lograron registrar cuatro modelos de este tipo de perrera en las estancias "Lazo", "Avelina", "Rio Verde" y "Monte León". Derivado de este modelo existió una subtipología presente, al menos, en las estancias "Tapi Aike" (Fig. l) y "Punta Delgada" (Fig. 3j) en el cual la perrera conforma un módulo para seis perros y dicho módulo se repite tantas veces como sea necesario. En los casos catastrados estos se repetían siete veces.

El segundo tipo de perrera corresponde a una de mayores dimensiones en cuanto a anchura y altura, y cuya longitud y forma adoptan la forma de una "U", con las puertas de algunos albergues hacía un espacio interior protegido y otras hacia un exterior expuesto. La primera referencia de este tipo de perrera la tenemos de una antigua fotografía tomada hacia 1918 en la estancia "Herminita" (Tierra del Fuego, Argentina), la cual figura con el título "Perrera sistema moderno" (Fig. 3a). El único modelo de este tipo de perrera que pudimos catastrar se encuentra ubicado en la estancia "San Gregorio" (Fig.3c, 3h). El edificio tiene veinte metros de largo por once de ancho y orienta su base hacia el viento dominante, puede albergar a sesenta perros.

Ambos diseños de perreras descritos poseían puertas correderas de maderas y los clásicos detalles estilísticos ornamentales ya conocidos entre ellos, lo pináculos. Las versiones modernas cuando se han ceñido a un patrón de diseño, lo adaptan de la primera modalidad descrita.

\section{c) Carnicería}

Todo establecimiento rural habitado de madera permanente requiere de una instalación para el faenamiento de los animales lanares de consumo. Situado siempre junto a un curso de agua natural (arroyo, chorrillo o brazo de un río) o artificial (canal) para el efecto de su mejor aseo y mantenimiento higiénico, consta de un edificio simple, a dos aguas, con espacio para trabajar con las reses y con un pequeño corral anexo para los animales destinados

pedigree de la raza Border Collie (un macho y dos hembras) con los que se formó un plantel de reproducción que se mantuvo operativo por largo tiempo. 

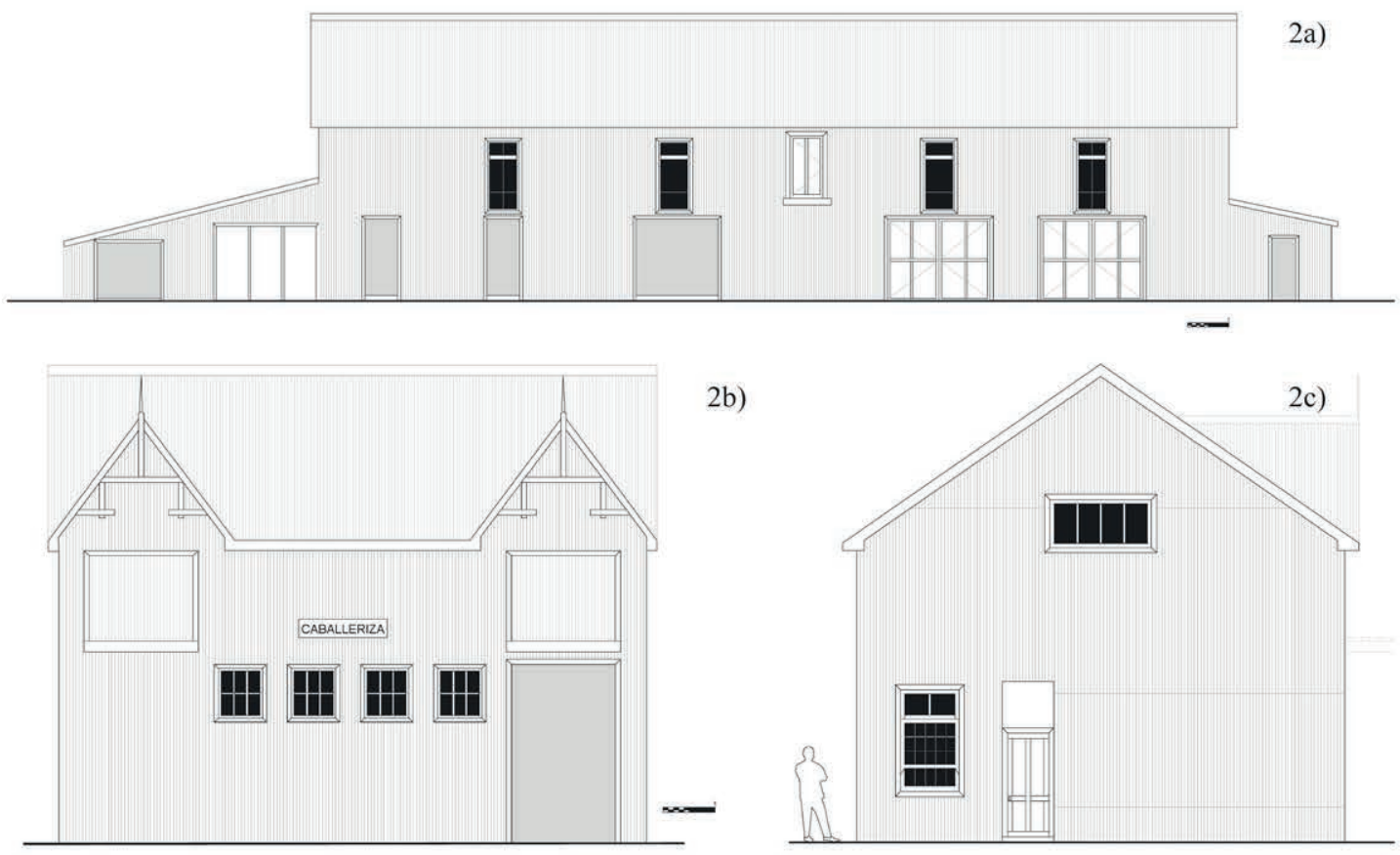

2b)
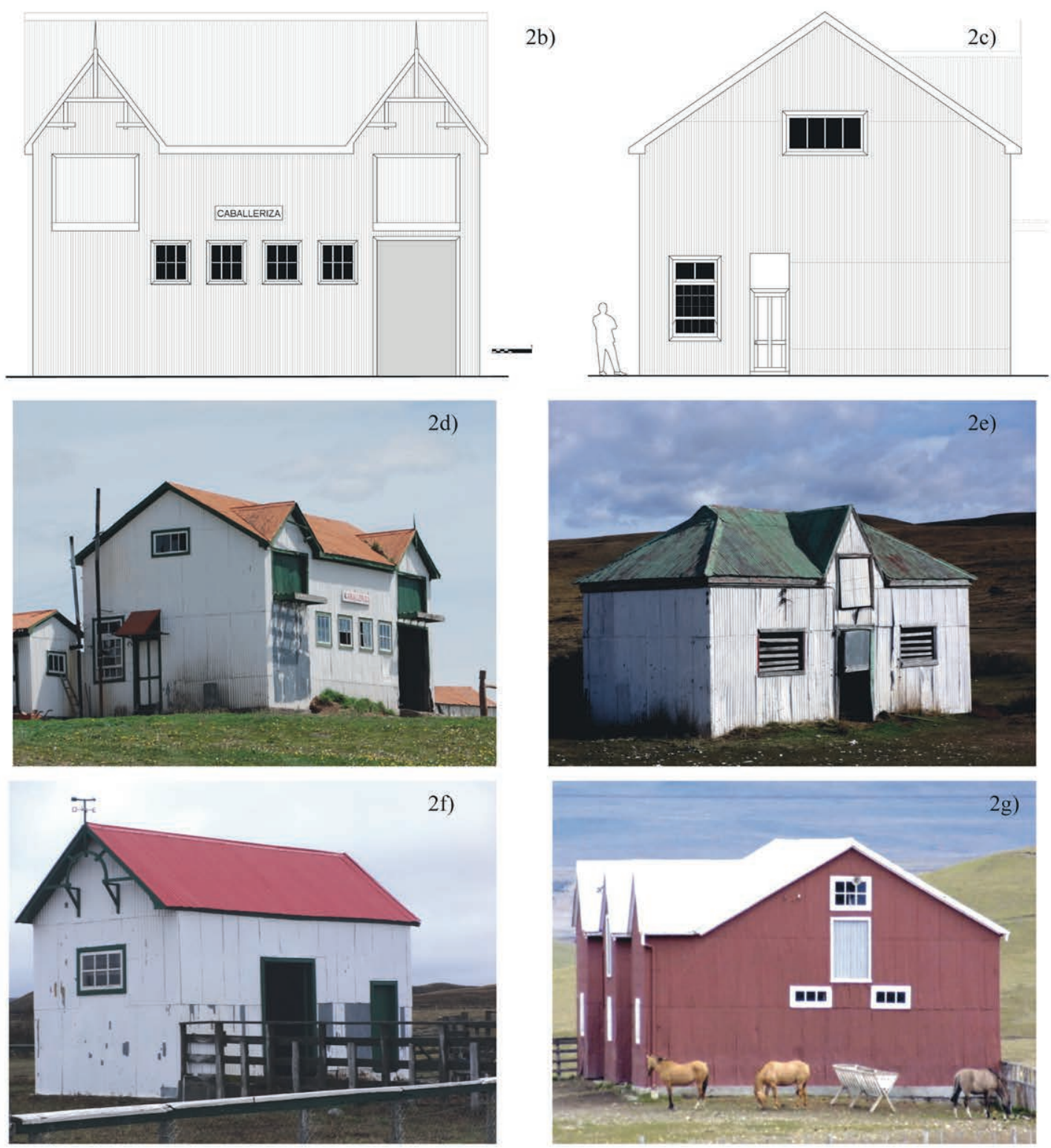

Fig. 2a) Caballeriza estancia "Rio Verde", dibujada a partir de una fotografía tomada hacia 1920. 2b) Elevación principal caballeriza estancia "Glencross". 2c) Elevación lateral. 2d) Caballeriza estancia "Glencross" (fotografía de Héctor Acuña). 2e) Estancia "Punta Delgada". 2f) Estancia "Avelina". 2g) Estancia "María Behety" (En: panoramio.com/photo/3266243). 
al sacrificio. Usualmente el piso interior del recinto es de cemento para su mejor aseo.

\section{d) Cochera o garage}

Pequeño espacio originalmente pensado y construido para estacionar carruajes de transporte personal (coches) de tiro cabalgar y sus atalajes, la introducción de automóviles a principios del siglo XX, generalizada a contar de las décadas de 1910 y 1920, vehículos ciertamente muy apreciados por los estancieros y/o sus administradores por las ventajas que los mismos poseían por sobre los primeros fueron desde el principio estacionados bajo techo para su debida protección de la intemperie. En uno y otros casos, el recinto correspondiente quedó situado en la inmediata proximidad a las habitaciones del conductor (propietario o usuario). Tanto en este caso, como en el de la carnicería y caballeriza, su utilidad funcional no prescindió de los aspectos estéticos y de ese modo, cada uno en su clase, respondió a formas arquitectónicas simples pero con detalles de construcción de carácter ornamental para su mejor lucimiento $e$ integración al conjunto edificado de los cascos de estancias.

\section{e) Paperas}

La papera es la forma más elemental de las edificaciones del género menor de la arquitectura rural patagónica. No sólo lo es porque la misma por lo común está excluida de todo diseño con alguna gracia estética, sino además porque en su construcción han podido (y pueden) utilizarse materiales desechables o sin mayor elaboración (troncos de árboles o partes de los mismos, trozos de maderas elaboradas, trozos de planchas de fierro cincado tambores aplanados, piedras, en fin). Pero, en el caso si esta parece haber sido y ser la norma general, hay alguna excepción singular $e$ interesante de suyo por cuanto representa un caso de tipología constructiva de arquitectura rural menor, según se describe más adelante.

La preservación de alimentos en antiguas

3 Este recinto de guarda y conservación de alimentos parece haber sido de uso común en Europa desde tiempo muy antiguo. Consta su presencia en Galicia (en zonas rurales) desde el siglo XVI con el nombre de "pozos de nieve", épocas de la colonización y primer desarrollo de la misma era un aspecto esencial para la vida de cuantos hacían de esa actividad la razón de sus existencias. Ello se comprende mejor cuando se tiene presente que los establecimientos rurales, estancias, se hallaban desperdigados por un territorio enorme, aislados entre sí y muy distantes de los centros poblados principales, contados por los demás, que eran tanto los abastecedores de bienes de diferente especie, como los receptores de los productos del trabajo rural. Fue el caso de Punta Arenas prácticamente el único centro de características urbanas del inmenso territorio sudpatagónico hasta el comienzo del siglo XX. Las comunicaciones se hicieron así necesariamente utilizando la vía marítima aprovechando la fisiografía interior territorial con grandes espacios de mar en forma del estrecho de Magallanes propiamente tal, canales secundarios, mares interiores y fiordos, lo que permitía acceder a caletas costeras desde donde caminos precarios, cuando los habían, permitían acceder hasta los distintos lugares en colonización, empleando para ello medios de transporte primitivos del tiro animal, insuficientes y limitados bajo diferentes aspectos. Entonces mantener los alimentos, o algunos de estos, en el mejor estado de conservación y duración posible en especial cuando estos productos eran el fruto de cultivos in situ, exigió creatividad e ingenio para resolver tal necesidad. Si se trato de una idea originalmente surgida de la experiencia cotidiana o anterior para alguno de los moradores del espacio rural o de un préstamo recibido de otras culturas, es cosa difícil de establecer. ${ }^{3}$

Fue este el caso característico de las "paperas" o también "sótanos", como en algunas partes se les ha nombrado y nombra, cuyo objeto preciso era y es el de preservar productos alimenticios de la huerta (papas, nabos, zanahorias, betarragas, coles, etc) en sus mejores condiciones de frescura y calidad para el consumo cotidiano o periódico. Para ello fue común que los espacios de guarda correspondientes se habilitaran aprovechando declives naturales del suelo (lomadas) de modo que permitieran la excavación o semi excavación de

edificaciones hechas con piedra y ladrillo bajo el nivel del suelo para habilitar espacios para la conservación de alimentos. 
2h)
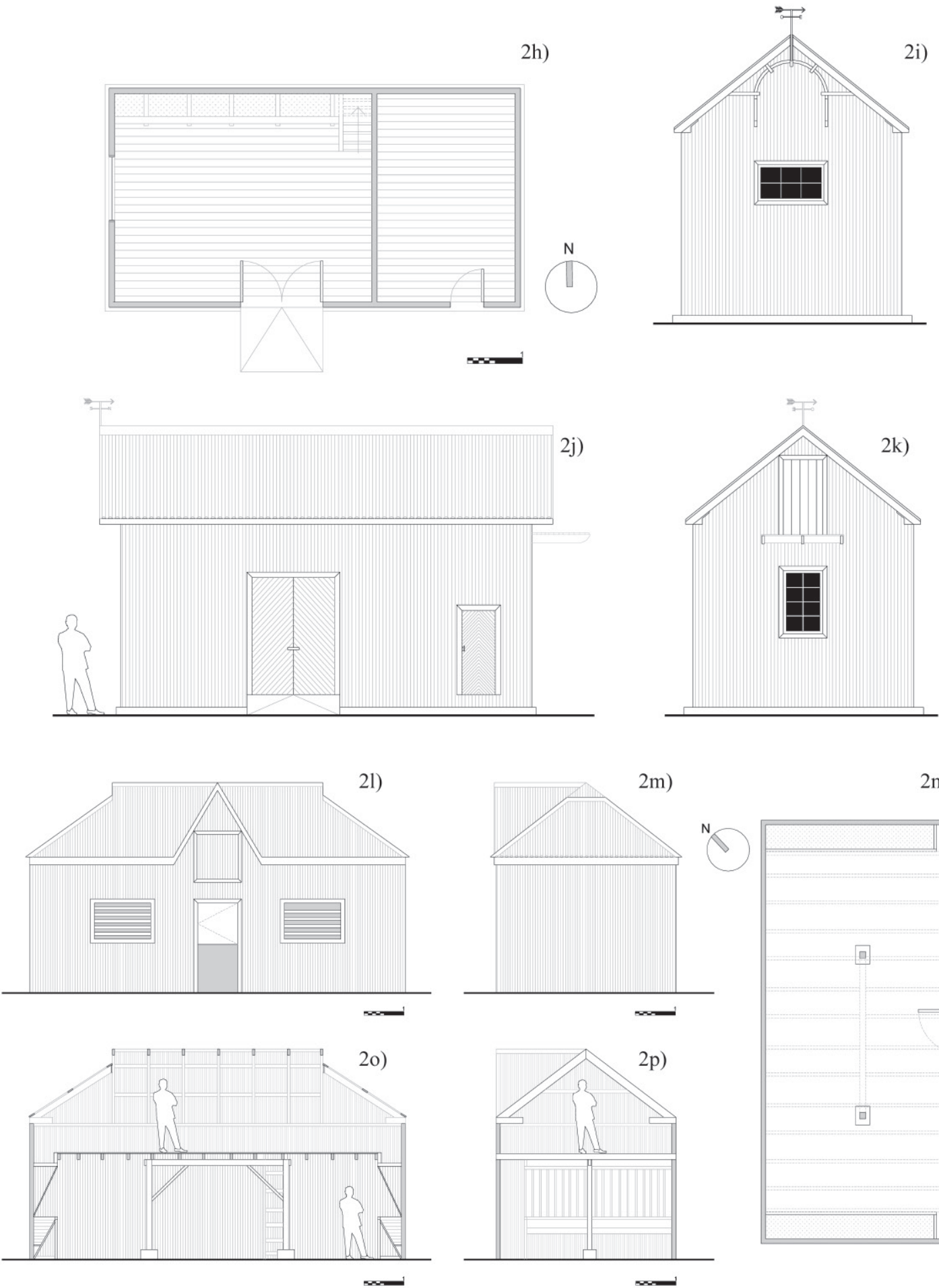

2n)

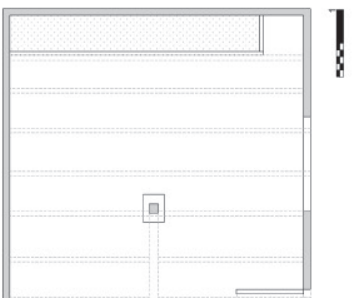

Fig. 2h) Planta caballeriza estancia "Avelina”. 2i) Elevación oeste. 2j) Elevación principal, 2k) Elevación este. 2l) Caballeriza estancia "Punta Delgada", elevación principal. 2m) Elevación noroeste. 2n). Planta. 2o) Corte longitudinal. 2p) Corte transversal. 
3a)
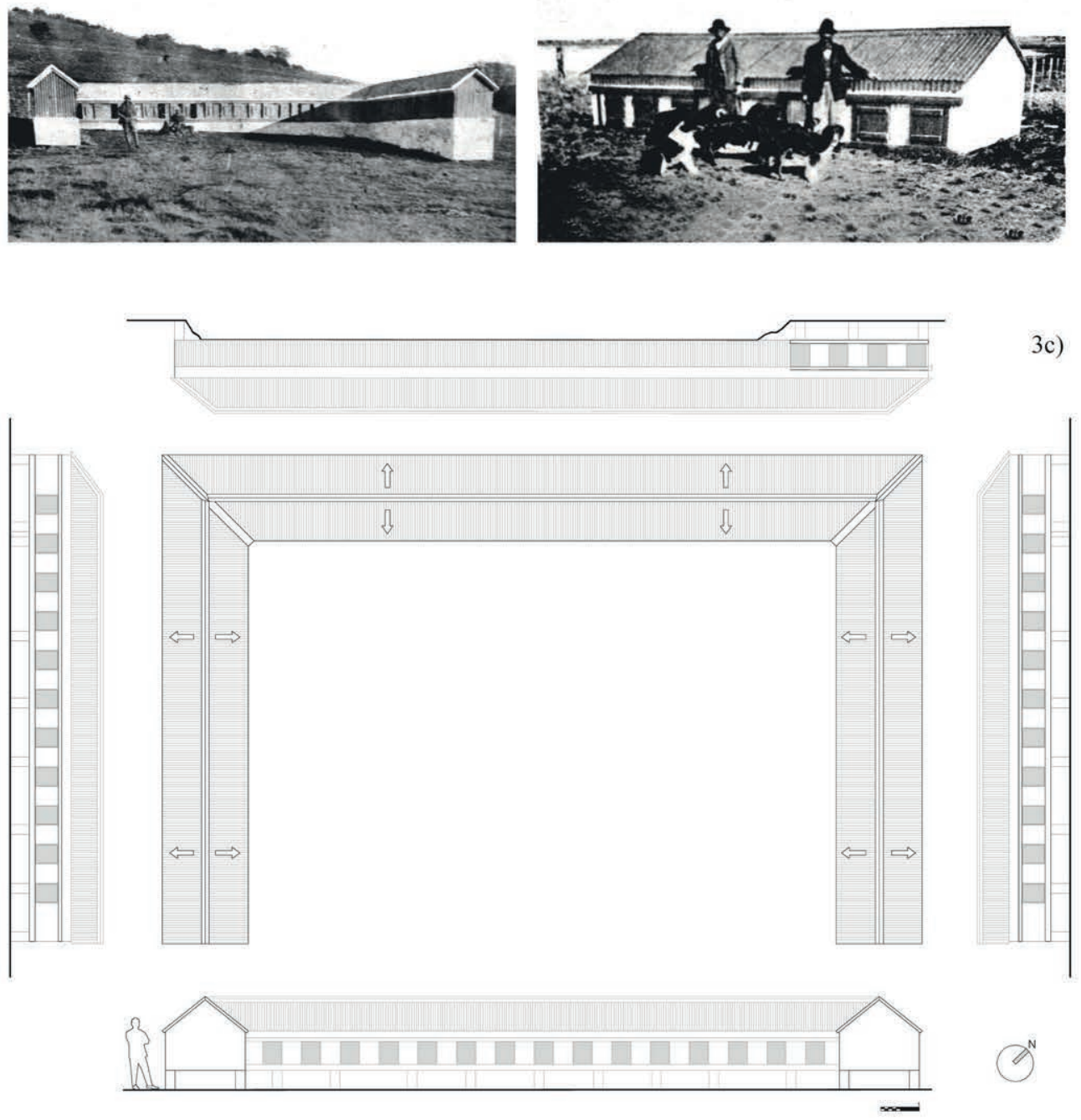

3d)
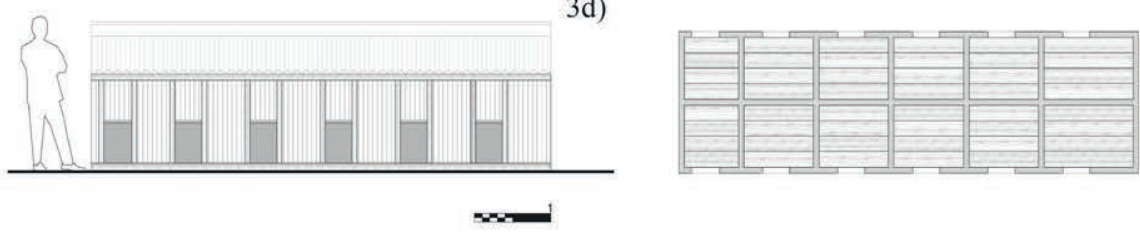

3e)
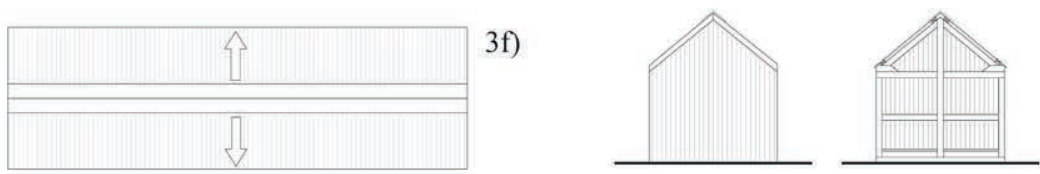

$3 g$ )

Fig. 3a) Perrera estancia "Herminita", imagen publicada en 1918 bajo el título "Perrera sistema moderno". 3b) Imagen publicada en 1924 bajo el título "La mansión de los perros ovejeros". 3c) planimetría perrera estancia "San Gregorio". 3d) Planimetría perrera estancia "Rio Verde". 3e) Planta. 3f) Planta de cubierta. 3g) Elevación tipo y detalle estructura de fachada. 



Fig. 3h,i) Perrera estancia "San Gregorio". 3j) Perrera estancia "Punta Delgada". 3k) Perrera estancia "Avelina", en una fotografía hacía 1930 ya figura en su misma ubicación actual. 3l) Perrera estancia "Tapi Aike", Argentina (fotografía de Joaquín Bascopé). 3m) Perrera estancia "Rio Verde". 3n) Perrera estancia "Monte León", Argentina (fotografía de Joaquín Bascopé). 
los mismos con alguna profundidad, cuyo objetivo preciso era el de aprovechar las condiciones naturales del suelo seco y bien aireado para la preservación de alimentos de origen vegetal en ambientes de homogeneidad térmica y baja humedad (Fig. 4). Así el espacio requerido tenía la pared del fondo, el piso y parte de los costados de tierra, que la inventiva completaba añadiendo lo faltante de los muros protectores, la techumbre y el frente donde se ubicaba la puerta de acceso.

Para este aspecto que conformaba la parte propiamente edificada del recinto se podían emplear, como se emplearon, diversos materiales según disponibilidad, tales como "champas", esto es, trozos de tierra vegetal cortados a modo de ladrillos que se colocaban sobrepuestos y sujetos entre palos verticales (Fig. 4c); o bien la misma combinación exteriormente por trozos de planchas de zinc, lo más común, o de tablazón de madera. Otras veces la estructura parietal principal era de "palo a pique" (secciones verticales de un tronco de árbol cortadas con hacha), cuyos intersticios se rellenaban con trozos de champa, aunque se prefería la primera variante descrita por ser las champas un buen aislante natural. La pared frontal del recinto edificado podía seguir el mismo patrón constructivo común, o sea, armazón de pies derechos de madera revestida exteriormente con tablas o chapas de fierro cincado, más la correspondiente puerta. La techumbre era de fierro cincado a dos aguas sobre tijerales elementales. Este era el tipo común de papera, también denominado "sótano" por carecer de ventanas y estar semi excavado en el suelo.

Cuando el establecimiento rural (o la habitación principal de una parte del mismo, caso de los puestos ovejeros) estaba ubicado naturalmente en sectores de planicies, sin lomadas próximas posibles de utilizar en sus declives, la edificación correspondiente se levantaba como una construcción rústica, armada con paredes de palos o madera elaboradas, entre cuyos parantes se ponían champas cortadas ex profeso, elemento que podía protegerse en todo o en parte de su superficie con trozos de lata (zinc) o tablas (Fig. 4a). La techumbre era siempre de fierro cincado en planchas onduladas.

Sin embargo de la caracterización general, en ambos variantes, cada papera podía tener sus propias características de diseño lo que se advertía tanto en la forma como en los materiales utilizados. La norma caracterizadora era la rusticidad y ningún lucimiento estético del conjunto, pues, por ejemplo, una papera casi nunca se pintaba como todas las demás edificaciones de la estancia con colores identificatorios. En ellas no se observa el estricto concepto académico importado desde Inglaterra y por el contrario, se ven con un diseño más libre y orgánico, donde la simetría, algo contradictorio al gusto, no existe rigurosamente. Pero sin embargo de este carácter, se han registrado formas que escapan al estereotipo y en la excepción hacen un tipo singular y único de arquitectura rural menor. Son los casos de dos recintos de la especie registrados en el casco de la antigua estancia "Cerro Guido" (Fig. 4b, 4d), que revelan planteamiento, empleo de materiales y formas de construcción que responden a un diseño arquitectónico sencillo pero interesante, digno de nota.

\section{OTROS CASOS}

\section{a) Torre de Agua}

Quizás este sea el único caso de los registrados en que su vigencia haya sido motivada antes por una razón más estética que utilitaria. En efecto, básicamente se ha tratado siempre (en los contados casos conocidos) de una construcción de protección o revestimiento para una instalación pre-existente como han sido los estanques de agua para el consumo humano. Estos han sido colocados a determinada altura del suelo puestos sobre pequeñas plataformas de madera integradas a su vez en una torre construida con maderos o vigas cuadradas unidas entre sí por piezas de madera, de considerable escuadría, puestas en diagonal y horizontal. Con la altura debida el estanque suministra por gravedad el agua mediante un sistema de cañerías con la fuerza y cantidad necesarios para el mejor uso del elemento. Cabe señalar que existen torres de agua que están integradas en una misma construcción (casa patronal por ejemplo) y otras que se ubican de forma autónoma. El segundo tipo de torres es el considerado en la presente investigación.

Pues bien, si en algunos casos lo descrito hace el todo construido, en otros y al parecer simplemente por razones estéticas, dada su 
ubicación en proximidad de las viviendas (caso de la casa patronal con ubicación en el recinto del jardín o la huerta), se ha revestido o cubierto el conjunto con una edificación ligera que se sobrepone, con techumbre a cuatro aguas y paredes de fierro cincado ondulado, debidamente pintado con los colores propios de cada establecimiento. Esta razón estética es particularmente notoria en al menos tres casos vistos. El primero de ellos corresponde a la torre de agua ubicada en el casco de la estancia "Caleta Josefina" (Tierra del Fuego, Chile) cuya estructura es de madera recubierta de zinc corrugado pintado de color blanco, con una cubierta a cuatro aguas pintada de color rojo, siguiendo así los patrones de colores que rigen e identifican a todo el casco de la estancia. El segundo caso de este tipo de torres de agua es la ubicada en la estancia "Rio Verde", emplazada precisamente en la parte posterior de la ex casa patronal. Esta construcción es idéntica en cuanto a colores (rojo granate, blanco y verde inglés) y paramentos ornamentales que rigen en la estancia (Fig. 5a, 5b, 5c), además posee en su parte superior un indicador, de forma circular, del estado de llenado del estanque con la iniciales " $F$ " $y$ " $E$ " que sin dudas corresponden a las iniciales de las palabras inglesas "Full" (lleno) y "Empty"

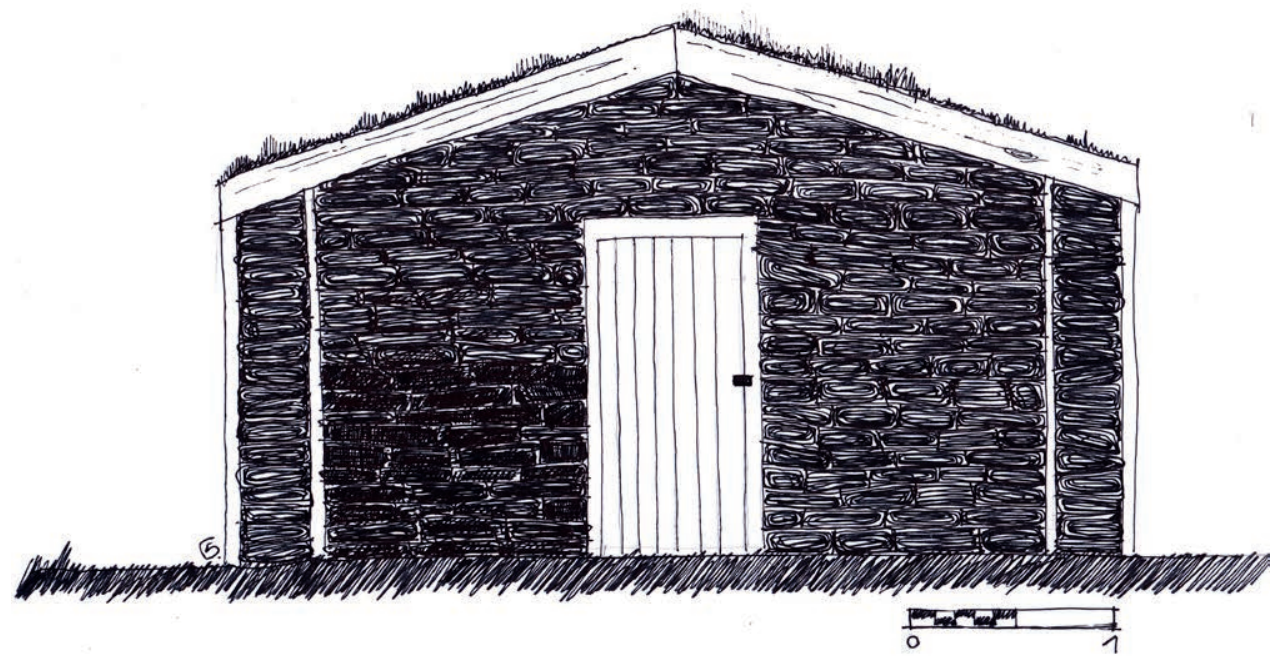

Fig. 4a) Papera de "champa" estancia "Rosa Emilia".

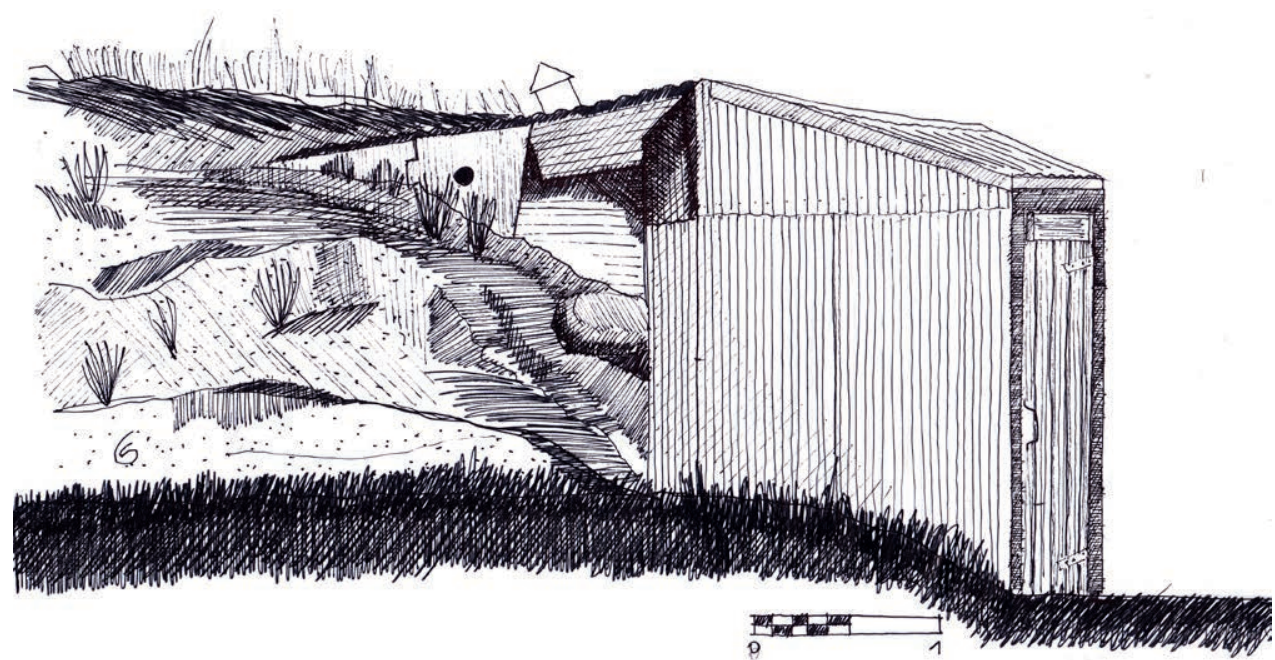

4b) Papera estancia "Cerro Guido". 


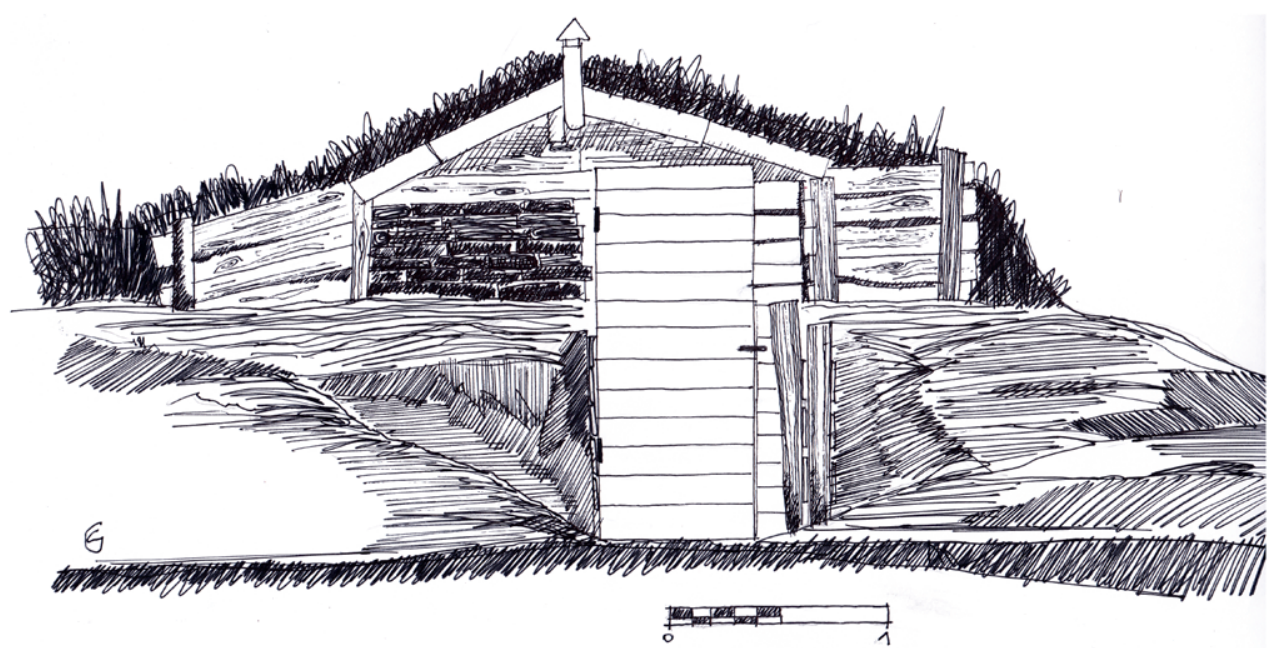

4c) Papera de "champa" estancia "Miriana" Tierra del Fuego (Chile).

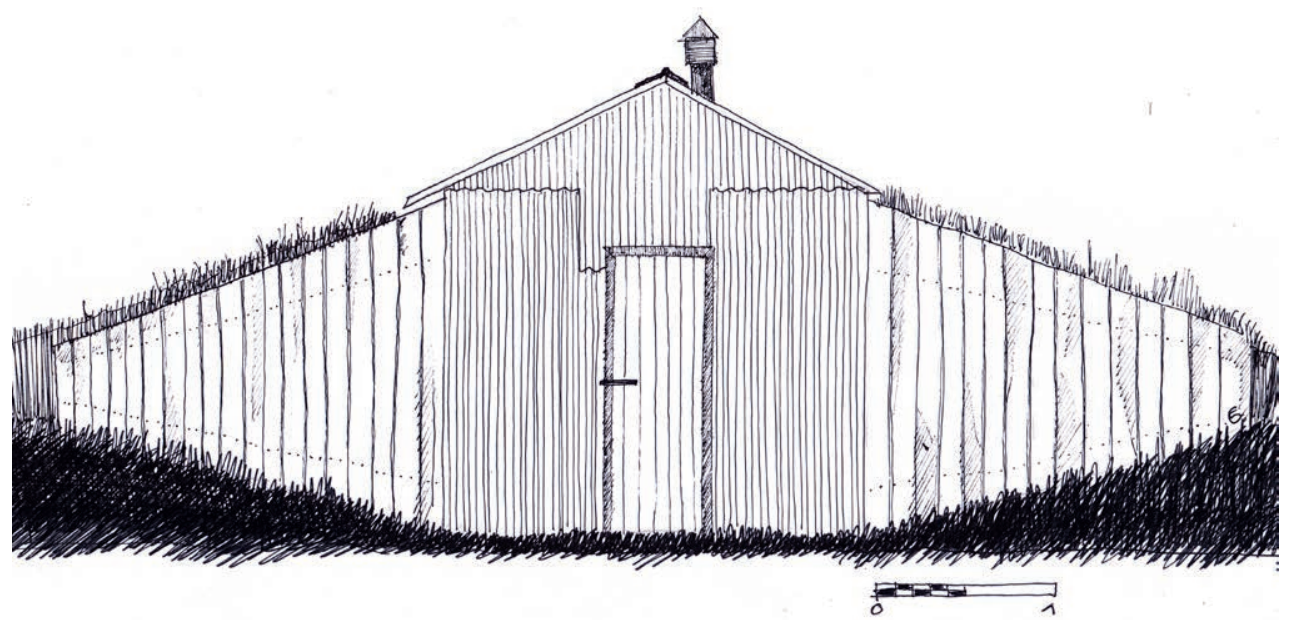

Fig. 4d) Papera estancia "Cerro Guido".

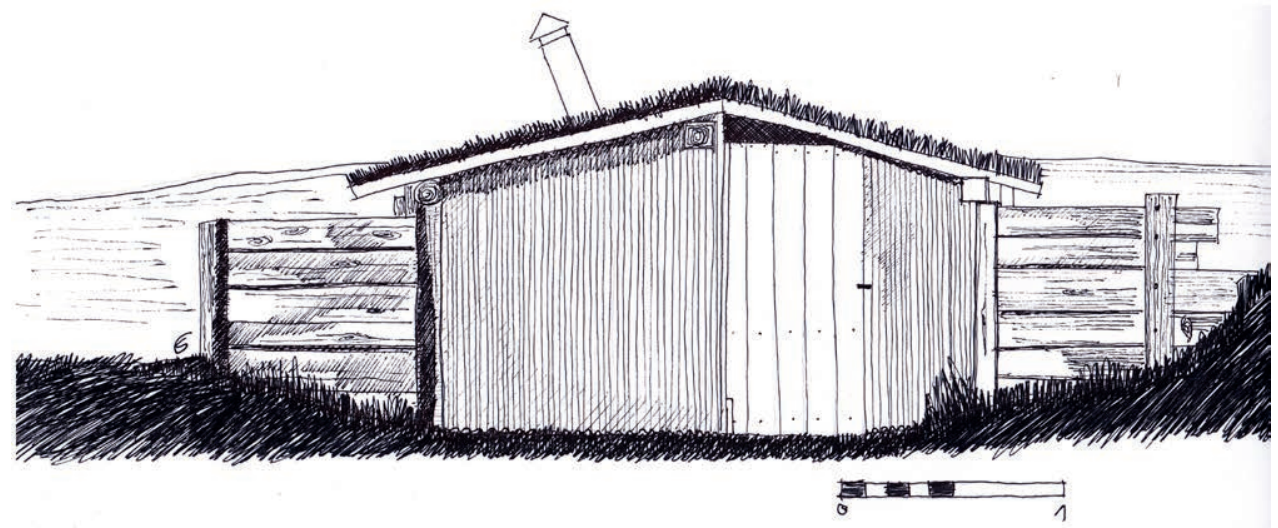

4e) Papera estancia "Cañadón Grande". 


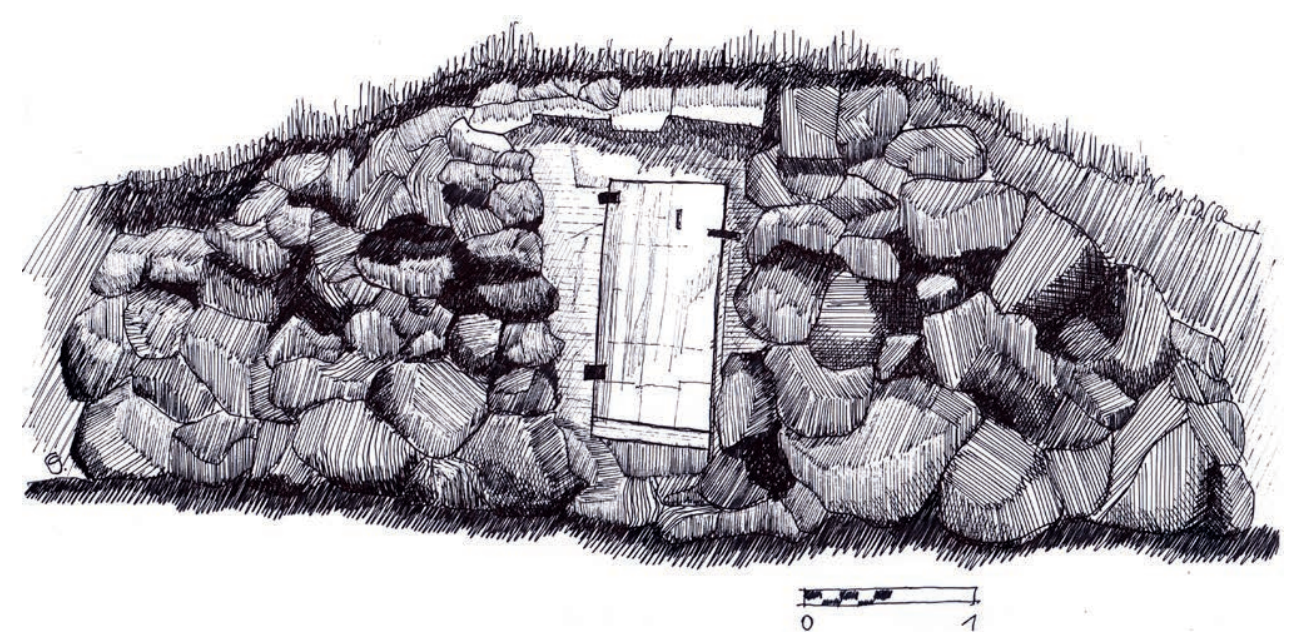

4f) Papera de piedra volcánica, localidad de "Río Chico".

(vacío). Por último existe el caso excepcional de la torre de agua del casco de la antigua estancia "San Gregorio" (Magallanes), en que la cobertura edificada asume la forma circular de una "torre medieval de defensa", con troneras y almenas (Fig. 5d).

\section{b) Carnicera, palomares y variados usos}

Estas formas son probablemente las menores en tamaño de cuantas se han registrados para el género de que se trata. El caso ejemplar es una estructura de tipo hexagonal, con seis paredes de celosía y una con puerta, cubierta a seis aguas (con una detallada estructura) con fierro cincado liso, coronado con una punta de adorno como remate. Se trata de una "carnicera" cuyo objeto exclusivo es el mantenimiento de carne faenada de res en condiciones de buena aireación para su consumo higiénico. Tradicionalmente en Magallanes esta necesidad se satisfacía antes de la llegada de los refrigeradores, ubicando en una suerte de estructura exterior en forma de caja con paredes y puerta de malla de alambre de manera tanto de permitir la ventilación de la carne allí se mantenía, como impedir el acceso de moscas $y$ insectos. La novedad del caso que se describe reside en que se trata de una construcción autónoma, que se mantiene en vecindad de la antigua casa patronal de la estancia "Vicuña" (Tierra del Fuego, Chile), y que sigue su mismo patrón de diseño en cuanto a color y volumetría
(Fig. 9a, 9g).

En cuanto a los palomares son construcciones escasas y solo se han tenido a la vista, para el efecto de esta investigación, únicamente dos. El primero corresponde al visible en una antigua y clásica fotografía de Alberto Bour, hacia 1906, del hotel fueguino "Cordón Baquedano". Al observar detenidamente esta imagen se puede apreciar en la cubierta, justamente sobre el acceso, un palomar con una cubierta a dos aguas que aún existía hasta 1960. El segundo palomar tenido a la vista esta ubicado en el casco de la estancia "Rio Verde" (Fig. 8). A diferencia del primero descrito, éste es de forma circular, se sostiene con un pilar de madera y posee tres orificios, su cubierta es coronada con un detalle ornamental, siguiendo así los mismos patrones estilísticos que la edificación que se ubica en su contigüidad.

En cuanto a construcciones con un destino de uso variado, podemos hacer mención a una torre emplazada en la parte posterior de la antigua casa patronal de la estancia "Rio Verde" (Fig. 6). Esta edificación tiene al menos cinco metros de altura, con una planta de unos tres por tres metros y se desconoce su uso original, algunas personas de la localidad donde se encuentra ubicada la reconocen como una carnicería luego que la construcción original destinada para dicho fin se destruyera a causa de un incendio, pero actualmente es usada como una bodega. Llama la atención el detalle de la construcción y su acabada terminación de la fachada en especial la estructura de su parte 

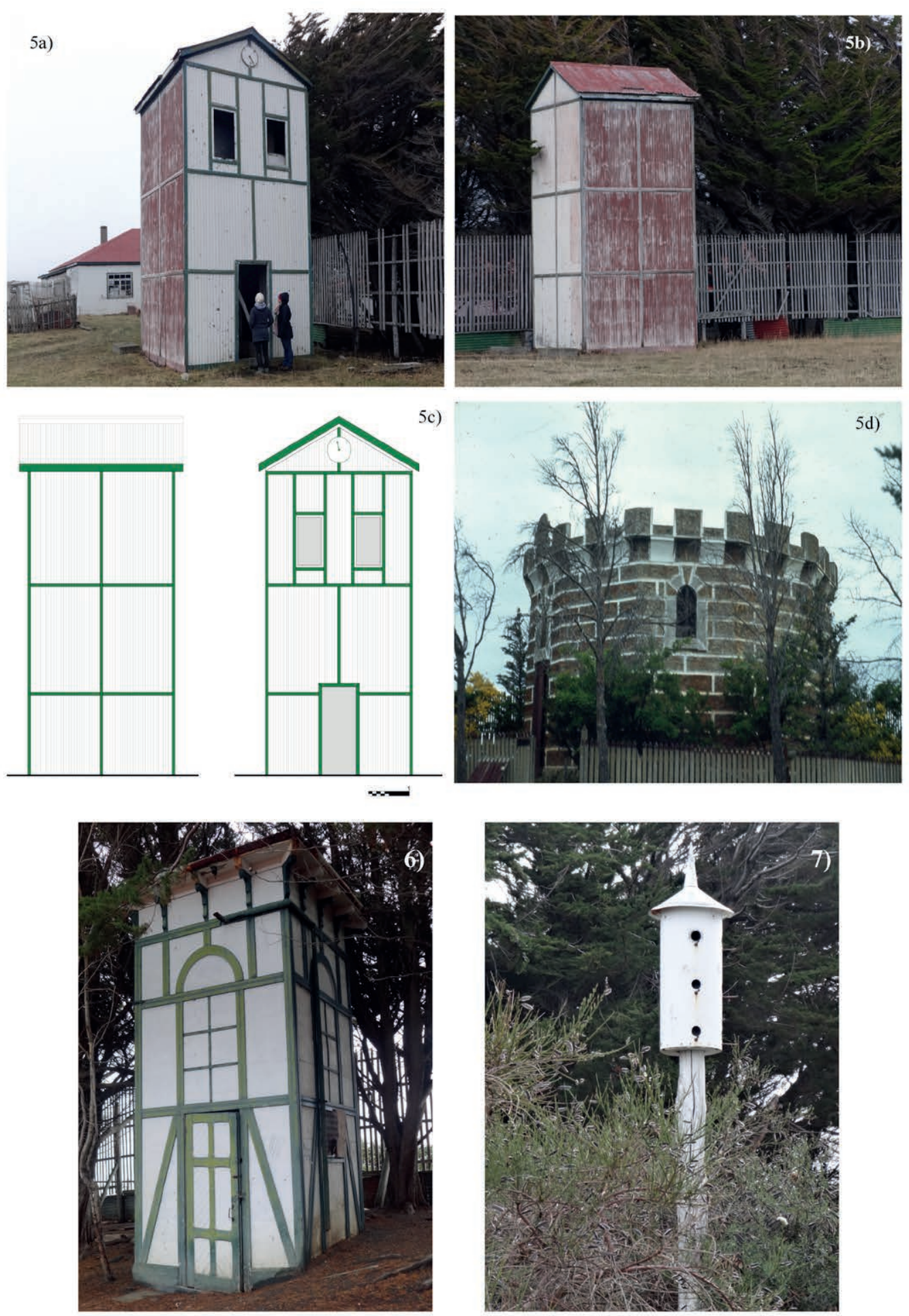

Fig. 5a,b) Torre de agua, estancia "Rio Verde". 5c) Elevación principal y lateral. 5d) Torre de Agua "Alfonso", estancia "San Gregorio", (Mateo Martinic B. 1980). 6) Edificación destinados a vario usos, estancia "Rio Verde" (2014). 7) Palomar, estancia "Rio Verde" (2014). 

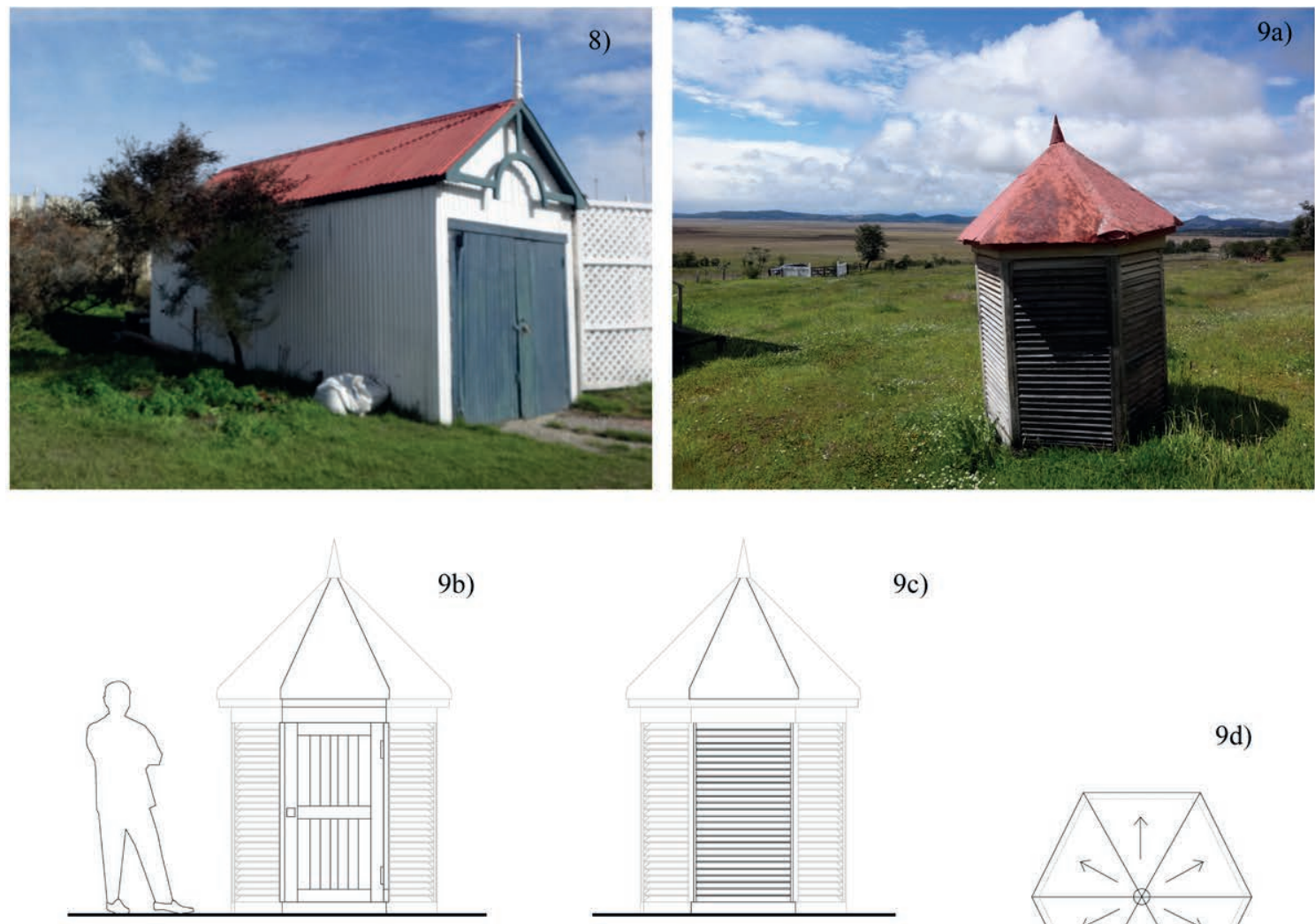

9c)
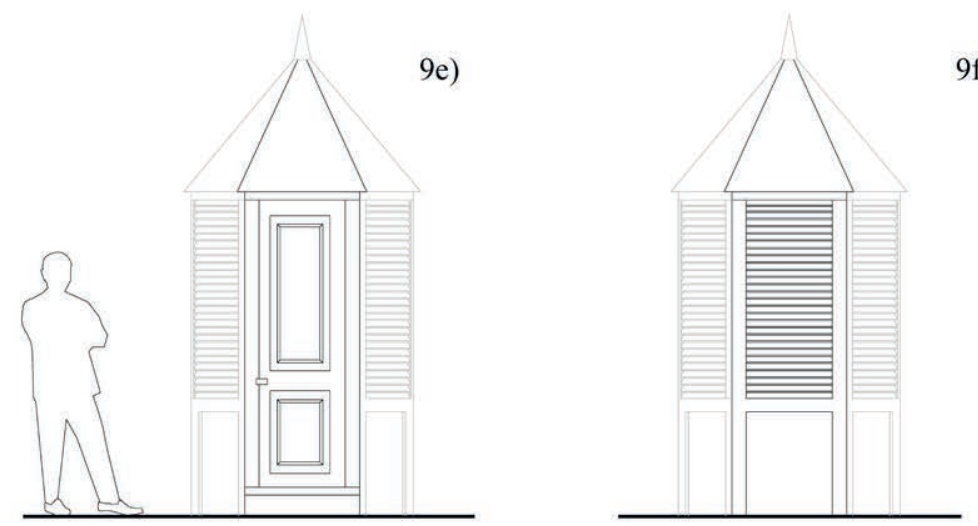

9d)

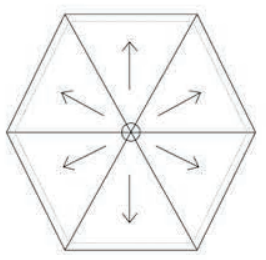

9f)

9g)

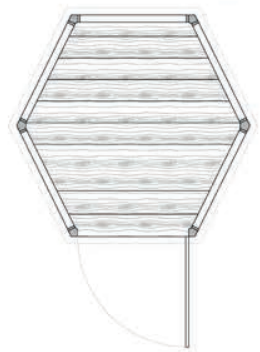

Fig. 8 Garage estancia "Punta Delgada". 9a) Carnicera estancia "Vicuña", Tierra del Fuego (Chile). 9b) Elevación principal. 9c) Elevación lateral. 9d) Planta de cubierta. 9e) Carnicera 2, estancia "Vicuña". 9f) Elevación lateral. 9g) Planta tipo carniceras.

superior que sostiene el alero que bordea toda la edificación. El diseño de esta torre, en cuanto a su fachada, se rige por el mismo patrón estilístico que caracteriza a la estancia "Rio Verde" (Fig. 5c).

\section{CONCLUSIONES}

El concepto de "Arquitectura Rural Menor" contribuye a completar el conocimiento acerca de las formas edificadas por el homo economicus 
en el ámbito rural sudpatagónico, como también ofrece a la sociología y/o antropología social de nuevos elementos para desarrollar y profundizar estudios particulares sobre las formas, contenidos y valores de vida en el espacio campesino. Por último contribuye al entendimiento del concepto "Paisaje cultural" particularizándolo en la noción visual del territorio estepario sudpatagonico-fueguino en una perspectiva que combina lo natural, como es la sugerencia de inmensidad propia de horizontes de terrenos llanos o plano-ondulados, reforzada comúnmente por la visión asociada del cielo siempre variable, según lo es la plasticidad de los conjuntos de nubes, con lo incorporado por el hombre en forma de establecimientos edificados que responden a una actividad económica, y a una forma o estilo de vida en libertad y aislamiento (donde la vecindad se mide en kilómetros).

Lo que más sorprende en la consideración de las formas tipológicas de arquitectura menor rural patagónica es que, sin embargo de su condición secundaria en un conjunto edificado, todas invariablemente, en especial en el caso de los cascos de estancia antiguos, responden a un estilo constructivo cuidadoso y, así parece, debidamente planificado y bien ejecutado. Si bien la mente creativa y el dibujo expresivo de ideas de diseño propios de un profesional de la arquitectura parecen haber estado ausentes directamente en cada uno de los tipos considerados, es evidente que en tan preciso aspecto ha debido existir una relación siquiera lejana, como inspiración, con los proyectos arquitectónicos de cada casco. También creemos que puede existir la posibilidad que los diseños en cuestión hayan sido adoptados, copiados o sencillamente creados a base de la existencia de planos de diseños establecidos como los divulgados en catálogos británicos para el caso de casas de administración, galpones etc. por las firmas Francis Morton \& Co, David Rowell \& Co. (Lolich, 2011). A falta de un profesional directamente involucrado quién mejor que un buen carpintero de obra, esto es, un artesano cultor de una especialidad antiquísima digna y noble, de honrosa tradición en las sociedades humanas. Y si los profesionales con estudios superiores en diseños arquitectónicos fueron más bien escasos en el período entre los siglos XIX al XX, tiempo histórico clave en el surgimiento, evolución $y$ desarrollo de la sociedad y economía magallánicas, de los segundos sí que los hubo y en mayor número además, nutrido como fue su contingente por maestros carpinteros calificados que emigraron desde Europa y se establecieron en Punta Arenas. Ellos fueron primero, como artesanos, ejecutores eficientes de las obras proyectadas por los profesionales de la construcción inmobiliaria, y luego, legatarios de su conocimiento especializado que supieron utilizar por años con magistral experticia, actuando algunos como proyectistas de obras, otros como bien calificados constructores y unos terceros como ambas cosas a la vez. Fueron los carpinteros de obras los protagonistas de la etapa constructiva que se ha denominado "Arquitectura sin arquitectos", vale decir, la de saber proyectar, pensando, planeando y ejecutando, haciéndolo con clase y calidad. Estamos ciertos que fue en la construcción de los cascos de estancia y otros establecimientos rurales de la Patagonia y Tierra del Fuego, donde esta conjunción de maestría en el diseño y en la ejecución fue cosa real y tangible, de valor práctico y estético en su hora y de clarísimo sentido patrimonial identificatorio y cultural en el presente.

Las construcciones denominadas "Arquitectura Rural Menor" continúan con la lógica de un sentido detallista estilístico plasmado en su fachada a veces "escenográfica", en lo superficial, y dejan una vez más claro la buena técnica y el conocimiento en el empleo y utilización de materiales de construcción, como lo es la madera, a diferentes escalas. Quizás la no valoración de la arquitectura rural menor se debe a que estas construcción no estuvieron destinadas para ser habitadas por el hombre aunque el mismo las haya pensado y ejecutado, conformando así parte de su hábitat. Lo que sin dudas reflejan estas construcciones es que la arquitectura era entendida como parte de un sistema mayor, un estilo académico establecido bajo un concepto dominante donde el pintoresquismo (op. cit), la simetría de los objetos, independiente de su escala, era lo correcto, lo aceptable y reflejaba el buen gusto y un estatus social. En definitiva, el dominio y la influencia británica se hacía (y se debía hacer) sentir hasta en los más mínimos detalles de los objetos, construcciones y arquitectura que se imponían en los suelos de la Patagonia y Tierra del Fuego, una estrategia nada al azar. 
El objetivo final de este trabajo académico ha sido el de poner en evidencia una realidad material desperdigada a lo largo y a lo ancho del territorio de Patagonia (en especial su zona meridional) y Tierra del Fuego, hasta ahora inadvertida y si lo ha sido, siempre infravalorada o, inclusive, incomprendida. Estamos convencidos de hacer con este trabajo una contribución para el mejor entendimiento de la adaptación de los humanos a este territorio y de su expresión tangible en el paisaje cultural. El mismo es una primera aproximación a la "Arquitectura Rural Menor”. Aún queda por realizar un análisis más profundo de las construcciones consideradas y determinar su relación y participación en un sistema mayor de planeamiento territorial como lo es el de la "Estancia Magallánica", evitando caer en descripciones "románticas" a través de un discurso arquitectónico intencionado y justificatorio.

Es de desear que algunos de tantos que comúnmente viajan por las carreteras patagónicas en automóvil, de cuando en cuando recorran el paisaje con la mirada para escudriñar "sus secretos" y "des-cubrir" de pronto detalles que en alguna otra ocasión anterior han sido pasados por alto. De ese modo será posible establecer un diálogo entre la mirada interrogante y el paisaje mudo que podrá concluir tal vez con una satisfactoria comprensión de aspectos tenidos por naturales, cuando en verdad son "naturalizados" y como tales el fruto de una prolongada convivencia adaptativa de los humanos de nuestra cultura a la tierra patagónica.

\section{AGRADECIMIENTOS}

Dejamos constancia de nuestros agradecimientos hacia Andrés Azua Sánchez, Daniela Peña Gatica, Nicolás Recabarren Traub y Julio Contreras por su colaboración en las salidas a terreno, a Nene Froesse por sus fotografías de la papera en la estancia "Rosa Emilia". También agradecemos a las siguientes personas que colaboraron de distintas formas en el desarrollo de esta investigación; John Nicol, estancia "Avelina". Manuel Rojas y José Leal, estancia "Punta Delgada". José Bauk, estancia "Miriana",
Flavia Morello, CEHA y a Joaquín Bascopé por sus referencias de perreras en la Patagonia Argentina.

\section{BIBLIOGRAFÍA}

Benavides, J. Martinic, M. Pizzi, M. \& Valenzuela, M. (1999). Las estancias magallánicas. Santiago: Universitaria.

Bosselin, M. Wenborne, G. Rolle, C. Saavedra \& Seisdedos, S. (2012). Punta Arenas y el País del agua. Santiago: Santander.

Cascardo, A. (1983). La construcción rural pionera en Última Esperanza, fines del siglo XIX hasta 1905. En: Actas del primer congreso de Historia de Magallanes. Instituto de la Patagonia, Universidad de Magallanes: Punta Arenas.

Díaz, C. (1919). Ganadería, Industria y Comercio del Territorio de Magallanes. Punta Arenas.

Garcés, E. Kroger, F. Martinic, M. Piwonka, N. \& Cooper, M. (2013). Tierra del Fuego: Historia, Arquitectura y Territorio. ARQ, Pontificie Universidad Católica de Chile: Santiago.

Iparraguirre, S. \& Von der Fecht, F. (2009). Tierra del Fuego; una biografía del fin del mundo. Buenos Aires: Vicente López Design.

Lolich, L. (2003). Patagonia. Arquitectura de estancias. Buenos Aires: CEDODAL.

Lolich, L. (2011). El patrimonio inmaterial como sistema. Efectos de la industrialización en la Patagonia. Apuntes 24(2), 257-274.

Mirelman, S. Lolich, L. \& Fernández, M. J. (2006). Arquitectura pionera de la Patagonia sur. Capítulos de la historia de Río Gallegos (1885-1940). Buenos Aires: Instituto Salesiano de Estudios Superiores.

Martinic, M. \& García, S. (2014). Arquitectura Rural Menor I. Magallania 42(1), 5-16.

Novoa, Z. (1982). Estancias Magallánicas. Seminario Facultad de Arquitectura y Urbanismo, Universidad de Chile: [s.e.].

Ribas, A. (S/Fecha). Álbum Ultima Esperanza. Punta Arenas: [s.e.].

S.A. Ganadera y Comercial "Menéndez Behety". (1924). Sociedad Anónima Ganadera y Comercial "Menendez Behety". Buenos Aires: Establecimiento Gráfico Argentino. 
